As shown in Table 1 , values of bound $\mathrm{Ca} / \mathrm{Mg}$ ratio in microsomes from various tissues incubated with ATP free medium did not differ. However, incubated with ATP containing modium, the ratio was increased. The increment was more marked in vas deferens and ileum, which were contracted by ATP, than in atria and taenia coli, which were relaxed. On the other hand, $\mathrm{Mg}^{+}$-ATPase activity was higher in atria and taenia coli than in vas deferens and ileum, while $\mathrm{Na}^{\prime}, \mathrm{K}^{\prime}$-ATPase activity did not differ to any great extent.

It has previously been demonstrated that increase in Ca/ $\mathrm{Mg}$ ratio of the medium enhanced the contractile response to ATP of the isolated smooth muscle (8). Morcover, with regard to contracile response of ATP, it has been postulated that exogenously applied ATP may increase Ca/Mgratio in the cell membrane, thereby favoring Ca entry and contraction (2). Present data appear to support the postulation. From present findings, it may be considered that in excitatory tissues, exogenously applied ATP is hydrolyzed very little and directly acts on the membrane, thereby favoring increase in $\mathrm{Ca}$ / $\mathrm{Mg}$ ratio, while in inhibitory tissues it is easily hydrolyzed and adenosine-like action of ATP is intensified.

\title{
REFERENCLS
}

1) Bursstork, G.: Pharmacol. Re'. 24, 509 (1972); 2) Danifl, E.E. And Irwin, J.: Can. J. Physiol. Pharmacol 43, 84 (1965); 3) Axtissoy, J. AND Holmiserr, B.: Acta physiol. scand. 75, $149(1969)$; 4) Gurarb.F. T. AND SLliATOR, W. It.: J. Pharmacol. exp. Ther. 148, 202 (1965); 5) Schnfider, W.C. avi Hogibom, G.H.: J. hiol. Chem. 183, 123 (1950); 6) Carvalho,

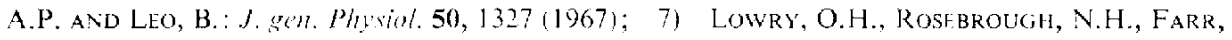
A.L. avd Ravdal.l, R.J.: J. hiol. Chem. 193, 256 (1951): 8) Hrdiva, P.D., Bovaccorsi, A. And Benve vuts, F.: limop. J. Pharmacol. 12, 249 (1970)

\section{FFFECTS OF 5-HYDROXYINDOLEACETIC ACID ON ISOLATED CANINE CEREBRAL ARTERIES}

\author{
Noboru TODA, Masakazu HOJO, Koichiro SAKAE and Hachiro USUI \\ Department of Pharmacology, Faculty of Medicine, Kyoto Universizy, Kyoto, Japan
}

Accepted April 10, 1974

Recent study in this laboratory has demonstrated that 5-hydroxykynurenamine (5HK) (1), converted from serotonin by trytophan 2, 3-dioxygenase (2) and formamidase, causes contrations of isolated canine cerebal arteries as does serotonim, and also attenuates the vascular response to serotonin (3). 5-Hydroxyindoleacetic acid (5-HIAA), a major metabolite of serotonin (4) via a catalysis of monoamine oxidase, has been shown 10 possess no or only slight serotonin-like activity in a variety of organs and tissues (57); however, litlle is known concerning interactions of this metabolite with scrotonin ac- 
tion. The present study was thus undertaken to investigate the effect of 5-HIAA and its interaction with serotonin in isolated canine cerebral arteries.

Basilar and posterior cerebral arteries $(0.3$ to $0.7 \mathrm{~mm}$ outside diameter) were isolated from mongrel dogs which had been anesthetized with sodium pentobarbital $(50 \mathrm{mg} / \mathrm{kg}$, ip) and sacrificed by bleeding from common carotid arteries. The vessels were cut helically into strips and vertically fixed under a resting tension of $1.5 \mathrm{~g}$ in a muscle bath containing modified Ringer's solution. The upper end of the strip was connected to a forcedisplacement transducer. The bathing medium was gassed with a mixture of $95 \% \mathrm{O}_{2}$

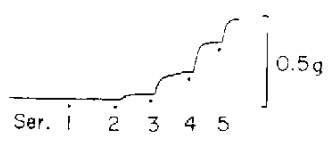

10 mir

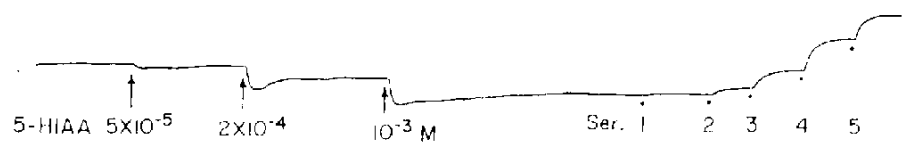

FIci. 1. Typical recordings of the response of a basilar arterial strip to serotonin and 5-HIAA. Concentrations of serotonin, from 1 to $5 ; 10^{-9}, 5 \times 10^{-9}, 2 \times 10^{-8}$, $10^{-7}$ and $5 \times 10^{-7} \mathrm{M}$, respectively.
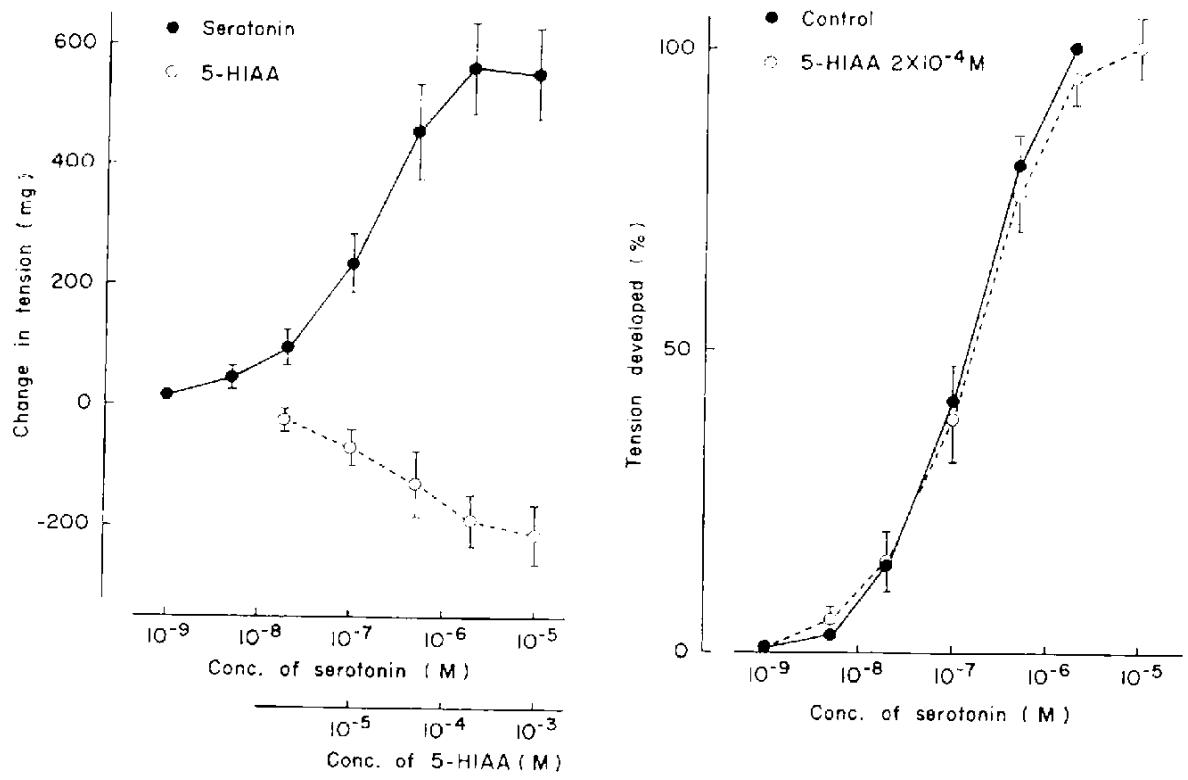

Fici. 2. Dose-response curves of serotonin and 5-HIAA (left) and dose-response curves of serotonin in the presence or absence of 5-HIAA (right). Vertical bars represent standard crrors of means. For the right figure, contractions caused by $2 \times 10^{-6} \mathrm{M}$ serotonin in control media were taken as $100 \%(645 \div 103$ $\mathrm{mg}, \mathrm{N}=6$ ). Numbers of preparations used : 5 for the left figure and 6 for the right. 
and $5 \% \mathrm{CO}_{2}$ and was maintained at $37 \div 0.5^{\circ} \mathrm{C}$. Serotonin creatinine sulfate and 5-HIAA were added directly to the bathing medium in cumulative concentrations. Details of the methods were described in an carlier report (8).

In cerebral arterial strips, serotonin in concentrations in a range from $10^{-8}$ to $2 \times 10^{-6}$ $M$ caused a dose-dependent increase in the tension. In contrast, 5-HIAA in concentrations from $10^{-5}$ to $10^{-3} \mathrm{M}$ elicited relaxation of these arteries in a dose-dependent manner (Fig. 1). Quantitative comparison of the response to serotonin and 5-HIAA obtained from the same arterial strips is presented in Fig. 2. The 5-HIAA-induced relaxation was more evident when the arteries had been contracted with prostaglandin $\mathrm{F}_{2 \mathrm{a}}\left(3 \times 10^{-7}\right.$ to $\left.10^{-6} \mathrm{M}\right)$. Relaxation induced by $5 \times 10^{-5} \mathrm{M} 5$-HIAA was not inhibited by $5: 10^{-6} \mathrm{M}$ propranolol in 3 out of 3 strips, $10^{-6} \mathrm{M}$ atropine in 2 out of 2 and $2 \times 10^{7} \mathrm{M}$ ouabain in 2 out of 2 . Thus, it appears that beta-adrenergic, cholinergic and electrogenic $\mathrm{Na}^{+}$pump mechanisms are not involved in the grenesis of the relaxation.

The dose-response relationship for serotonin was not altered when cerebral arterial strips were trated for $20 \mathrm{~min}$ with $2 \therefore 10^{-4} \mathrm{M}$-HIAA $(26 \pm 18 \mathrm{mg}$ relaxation, $\mathrm{N}=6)$ (Fig. 2 -right). In 2 preparations, further increase in the concentration of 5-HIAA to $10^{-3} \mathrm{M}$ did not influence the contractile response to serotonin (Fig. 1).

Our study demonstrated that the deaminated metabolite of serotonin, 5-HIAA, showed neither serotonin-like nor aiti-serotonin action on isolated canine cerebral arteries, while in contrast a metabolite of serotonin. 5-HK, of which the indole ring was opened possessed both serolonin-like and anti-serutonin actions (3).

\title{
REFERENCES
}

1) Makino, K.: Biochem. biophys. Res. Commun. 5, 481 (1961); 2) Hiraia, F. and Hayaishi, O.: Binchem. biophlys. Res. Commum. 47, 1112 (1972); 3) Toda, N., Toklyama, T., Sfanoh, S., Hirata, F. and Hayaishi, O.: Proc. natm. Acad. Sci. 71, 122 (1974); 4) Udenkritad, S., Tites, E., AvD Wlissbach, H.: I. hiol, (hom. 219, 335 (1956); 5) Grfinberg, M.J.: Br. I. Pharmacol. Chemother. 15, 375 (1960): 6) CuRTIS, D.R. AND DAvis, R.: Br. I. Pharmacol. Chemother, 18, 217 (1962): 7) Cinong, G.C., And Pillelis, J.W.: Br. J. Pharmacol. Chemother. 25, 481 (1965); 8) TODA, N. AND FuJtTA, Y.: Circulation Res. 33, 98 (1973)

\section{COMPARISON OF N-OXIDATION AND N-DEMETHYLATION OF DIMETHYLANILINE IN HUMAN LIVER}

\author{
Mitsukazu KITADA, Tetsuya KAMATAKI and Haruo KITAGAWA \\ Department of Biochemical Pharmacology, Faculty of Pharmaceutical Sciences. \\ Unversity of Chiba, Chiba, Japan \\ Accepted May 1, 1974
}

A numbur of tertiary amine irugs have been demonstrated 10 undergo two main oxidative reactions by hepatis-microsomal enzymes requiring both NADPH and molecular oxygen. One is $\mathrm{N}$-demethylation reaction which is catalyzed by cytochrome P-450, a 